\title{
ANALISIS KOREOGRAFI TARI GANJUR PADA UPACARA ADAT ERAU KUTAI KERTANEGARA KABUPATEN KUTAI KERTANEGARA, KALIMANTAN TIMUR
}

\author{
Oleh: Agus Yulianti \\ Pembimbing Tugas Akhir: Dra. Supriyanti, M.Hum dan Drs. Surojo, M.Sn \\ Jurusan Tari, Fakultas Seni Pertunjukan Institut Seni Indonesia Yogyakarta \\ Alamat Email: yuli29agusyulianti@gmail.com
}

\begin{abstract}
RINGKASAN
Tari Ganjur merupakan kesenian yang berbentuk ritual dalam sebuah upacara adat yaitu Upacara Erau adat Kutai Kartanegara Ing Martadipura, yang dilestarikan oleh masyarakat kota Tenggarong, kabupaten Kutai Kartanegara, Kalimantan Timur.Tari Ganjur merupakan tarian Klasik yang dimiliki oleh Kesultanan Kutai Kartanegara Ing Martadipura dalam bentuk koreografi kelompok, karena dapat dilihat dari bentuk pertunjukan tari ganjur yang ditarikan oleh empat penari laik-laki. Di dalam tari Ganjur menggunakan sebuah properti Gada yang biasa disebut dengan ganjur. Tari Ganjur menggambarkan seorang pangeran yang sedang menjaga keamanan tiang ayu agar pada saat acara Bepelas Sultan tidak diganggu oleh roh-roh jahat. Tari Ganjur mengenakan busana atasan miskat sedangkan bawahannya mengenakan celana panjang berwarna hitam dipadukan dengan sarung Samarinda. Rias penari menggunakan rias natural, serta iringan tari menggunakan seperangkat alat gamelan Kutai.

Dalam hal ini yang menjadi pokok permasalahan adalah analisis koreografi tari Ganjur pada Upacara Erau Adat Kutai Kartanegara Ing Martadipura. Untuk menjawab permasalahan tersebut, maka akan meminjam teori Y. Sumandiyo Hadi mengenai Koreografi Bentuk-Teknik-Isi. Menurut Y. Sumandiyo Hadi ketiga konsep bentuk, teknik, dan isi ini tidak dapat dipisahkan dalam sebuah pertunjukan tari. Dalam penelitian ini tari Ganjur pada Upacara Erau Adat Kutai Kartanegara Ing Martadipura dapat ditinjau dari aspek bentuk, teknik, dan isi. Aspek bentuk tari Ganjur terbagi menjadi tiga bagian, pembagian ini terlihat dari perpindahan iringan musiknya. Aspek teknik gerak tari Ganjur terdapat kesamaan dengan gerak tari Klasik yang ada di Surakarta dan Yogyakarta. Aspek isi tari Ganjur bertemakan keamanan yang bertujuan untuk menjaga keamanan daerah sekeliling Tiang Ayu. Kehadiran tari Ganjur dalam upacara Erau adat Kutai Kartanegara Ing Martadipura sangat berperan penting dalam acara bepelas sultan, karena kehadirannya diperuntukan
\end{abstract}


menurunkan Pangeran Sri Ganjur untuk menjaga keamanan tiang ayu dari roh-roh jahat, dan kehadirannya selalu ada pada malam Bepelas Sultan.

Kata Kunci : Tari Ganjur, identitas, Upacara Erau

\section{ABSTRACT}

Ganjur dance is a ritual art form in a traditional ceremony that is customary Erau ceremony Kutai Ing Martadipura, preserved by the people of Tenggarong city, district, Kutai, East Borneo. Ganjur dance a classical dance that is owned by the Sultanate of Kutai Ing Martadipura in the form of choreography Group, because it can be seen from the form of dance performances ganjur danced by four male-male dancers. In Ganjur dance uses a property called Gada commonly called ganjur. Ganjur Dance depicts a prince who is guarding the security pole so that at the time of the Sultan Bepelas event is not disturbed by evil spirits. Ganjur Dance wearing a clothing top miskat while his subordinates dressed in black trousers combined with sarong Samarinda. The dancers makeup using natural makeup, dance accompaniment using a set of Kutai gamelan instruments.

In this case an issue of concern is the analysis of dance choreography Ganjur Ceremony Indigenous Erau Martadipura Kutai Ing. To answer these problems, it will borrow Y. Sumandiyo Hadi theory regarding Choreography Form-Fill-technique. According to Y. Sumandiyo Hadi these three concepts of form, technique, and content can not be separated in a dance performance. In this study dance Ganjur Ceremony Indigenous Erau Kutai Ing Martadipura can be viewed from the aspect of forms, techniques, and content. Aspects of dance form Ganjur is divided into three parts, this division is seen from the transfer of musical accompaniment. Techniques of motion dance movement Ganjur there are similarities with Classical dance movement in Surakarta and Yogyakarta. Aspects of dance contents Ganjur themed security that aims to maintain the security of the surrounding area Tiang Ayu. The presence of dance in the ceremony Ganjur custom Erau Kutai Ing Martadipura very important role in the event bepelas sultan, because his presence is intended to lower the Prince Sri Ganjur to maintain the security of ayu pole of evil spirits, and his presence is always there at night Bepelas Sultan.

Key words: Ganjur Dance, Identity, Erau Ceremony 


\section{JOGED}

ISSN: $1858-3989$
Agus Yulianti (ANALISIS KOREOGRAFI TARI GANJUR PADA UPACARA ADAT ERAU KUTAI KERTANEGARA KABUPATEN KUTAI KERTANEGARA, KALIMANTAN TIMUR)

\section{PENDAHULUAN}

Tenggarong merupakan sebuah kecamatan yang menjadi ibukota Kabupaten Kutai Kartanegara, Kalimantan Timur. Kota ini juga merupakan ibukota Kesultanan Kutai Kartanegara Ing Martadipura sejak 28 September 1782, sehingga kota ini mendapat julukan " Tenggarong Kota Raja" (Murhansyah, 2006; 3). Kota Tenggarong memiliki berbagai keanekaragaman seni dan budaya yang menjadikannya sebagai kota wisata di Kalimantan Timur. Ada beberapa objek wisata yang dapat ditemui di Tenggarong di antaranya Museum Mulawarman, Musem Kayu Tuah Himba, Pulau Kumala, Kesultanan Kutai Kartanegara Ing Martadipura, dan lain-lain. Kota ini juga terbilang memiliki daya tarik yang tinggi karena ada penyelenggaraan Upacara adat Erau. Upacara ini digelar oleh pihak Kesultanan Kutai Kartanegara Ing Martadipura yang bekerjasama dengan Pemerintah Kabupaten Kutai Kartanegara.

Erau secara etimologi berasal dari kata "serau" yang artinya nunu/bakar, sehingga menimbulkan rame, seperti nunu atau bakar teberau. Erau secara terminologi yaitu rame atau gaduh seperti berpesta pora, bersuka ria menunjukkan keberhasilan. Jadi, Erau secara umum merupakan suatu kegiatan yang bertujuan meramaikan dan menghibur masyarakat, bermakna baik, sakral, ritual dan kegembiraan ( Adji Zamrul Syalehin, 2000; 2). Erau dilaksanakan satu tahun satu kali, selama tujuh hari delapan malam. Kegitan Erau merupakan tanda syukur masyarakat terhadap rahmat dan nikmat yang diberikan oleh yang maha kuasa sehingga mereka berhasil dalam berladang dan berusaha seperti dalam bidang berdagang.

Salah satu susunan acara pada Upacara Erau adat Kutai Kartanegara Ing Martadipura adalah Bepelas Sultan. Sebelum Sultan Kutai Kartanegara Bepelas terlebih dahulu ditampilkan beberapa tarian Kesultanan Kutai Kertanegara yang sakral, bertujuan untuk menjaga dan melindungi jalannya acara Bepelas Sultan di Tiang Ayu, dari perbuatan roh-roh yang jahat. Salah satu tarian yang sakral adalah Tari Ganjur.

Tari Ganjur adalah tarian yang menurunkan Sangyang Sri Gamboh dan Pangeran Sri Ganjur. Tarian ini bermaksud untuk meminta restu kepada Sangyang Sri Gamboh dan Pangeran Sri Ganjur agar pada saat Bepelas sultan dijauhkan dari roh-roh jahat. Tarian ini memakai Gada berwarna kuning bertingkat tiga, yang ditarikan oleh empat laki-laki yang bertujuan untuk menjaga keamanan sekitar Tiang Ayu ( Harry Bachroel, 2009; 151). Sebelum dimulainya tari Ganjur terlebih dahulu Pawang Dewa melaksanakan memang untuk mengundang Pangeran Sri 
Ganjur, yang diiringi oleh alunan seruling dan diikuti oleh Dewa menaruhkan empat buah ikat kepala dan empat buah gada pada dua buah baki, dengan diiringi Dewa memang maka turunlah empat laki-laki, dua orang di sisi kanan dan dua orang di sisi kiri untuk menarikan tari Ganjur. Penari memasang ikat kepala dan memegang Gada sambil menari menempati empat sudut, berputar diiringin gamelan alunan irama ganjur. Pada saat tari Ganjur dimulai, empat pakwon bini berdiri di sudut menyalakan lilin sampai tarian selesai.

Tarian ini terdapat kesamaan gerak dengan gerak-gerak tari Klasik gaya Surakarta dan Yogyakarta, terdapat ukel, nyempurit dan ngithing. Gerakan kakinya segaris membuka serta agak merendah seperti mendhak seperti tari klasik gaya Surakarta dan Yogyakarta. Tarian ini berjalan ke arah empat sudut, kemudian bertemu di tengah-tengah, sambil mengadu Ganjur yang disebut perang Ganjur, bentuk gerak perang ini sama seperti perang Gada pada tarian Klasik gaya Surakarta dan Yogyakarta. Tarian diiringi dengan seperangkat Gamelan Kutai yang slendro terdiri dari Demung, Saron, Bonang, Gender, dan Kendang yang sama persis dengan Gamelan yang berada di Jawa.

Tata rias dan busana merupakan bagian yang penting dalam sebuah pertunjukan. Tata rias pada Tari Ganjur ini tidak ada riasan khusus untuk para penarinya. Melainkan tidak berias atau natural karena yang menarikan juga pria. Tarian ini bersifat sakral dan ritual maka tidak adanya riasan yang khusus untuk penari Ganjur ini. Kostum yang digunakan untuk penari Pria disebut miskat untuk bagian atas dan celana hitam untuk bagian bawah yang dipadukan oleh sarung Samarinda dan ikat kepala dari tali besar yang terjalin menjadi satu dalam tiga warna yaitu, merah, kuning, dan hitam.

Tempat Pentas Tari Ganjur pada Upacara Erau adat Kutai Kartanegara Ing Martadipura menggunakan ruangan tertutup. Penonton menyaksikan tarian ini hanya kalangan keraton, atau kerabat keraton, serta tamu undangan saja, seperti pejabat daerah setempat. Tempat pementasannya di dalam Museum Mulawarman, yang dahulu adalah Keraton Kutai Kartanegara. Namun beralihnya masa pemerintahan maka keraton diberikan kepada Pemerintahan Daerah Kutai Kartanegara dan dijadikan sebuah museum, yaitu Museum Mulawarman. Tempat pementasan Tari Ganjur ini tidak dibuatkan panggung khusus, melainkan di tempat yang sederhana yaitu di sekeliling Tiang Ayu. Area atau tempat pentas Tari Ganjur disebut dengan stinggil.

Tari Ganjur pada Upacara Erau adat Kutai Kartanegara Ing Martadipura sebagai tari Klasik Kesultanan Kutai Kartanegara Ing Martadipura yang bersifat ritual dan memiliki 


\section{JOGED}

ISSN: $1858-3989$
Agus Yulianti (ANALISIS KOREOGRAFI TARI GANJUR PADA UPACARA ADAT ERAU KUTAI KERTANEGARA KABUPATEN KUTAI KERTANEGARA, KALIMANTAN TIMUR) kekuatan sakral yang sangat tinggi. Sehingga keberadaannya pun tidak terlepas dari dukungan masyarakat kalangan Kesultanan Kutai Kartanegara Ing Martadipura dan Upacara Erau adat Kutai Kartanegara Ing Martadipura pada acara Bepelas Sultan. Dari pembahasan diatas penulis ingin mengetahui bagaimana analisis koreografi Tari Ganjur pada Upacara Erau Adat Kutai Kartanegara Ing Martadipura. Untuk membedah permasalahan tersebut, maka akan meminjam teori Y. Sumandiyo Hadi mengenai Koreografi Bentuk-Teknik-Isi. Y. Sumandiyo Hadi, menjelaskan ketiga konsep bentuk, teknik, isi, merupakan satu kesatuan dalam bentuk tari dan tidak dapat dipisahkan. Proses pembentukan karya seni tercipta dari masyarakat pendukungnnya. Dapat diketahui bahwa masyarakat adalah sumber utama dari yang mereka ungkapkan, kemudian diwujudkan dengan suatu bentuk, dan salah satu bentuknya adalah sebuah tarian.

\section{PEMBAHASAN}

A. Analisis Koreografi Tari Ganjur Pada Upacara Erau Adat Kutai Kartanegara Ing Martadipura Ditinjau Dalam Aspek Bentuk, Teknik, Isi

\section{Aspek Bentuk Tari}

Sajian tari dapat dilihat dari segi bentuknya, maka tarian terbentuk dari adanya gerak, pola lantai, pengulangan gerak serta perpindahan dari motif satu ke motif lainnya. Bentuk tari dalam pengertian koreografi dapat diartikan sebagai hasil dari berbagai elemen tari yaitu, gerak, ruang, dan waktu yang nampak secara empirik struktur luarnya saja ( surface structure ), tanpa memperhatikan aspek isi atau struktur dalamnya ( deep structure ) (Y Sumandiyo Hadi, 2012; 39). Motif gerak mempunyai ciri-ciri tertentu yaitu terdapat awalan dan akhiran yang jelas sehingga dapat dilakukan secara berulangulang, mempunyai arti atau makna, memiliki teknik, dan melibatkan totalitas tubuh saat bergerak. Prinsip-prinsip kebentukan yang menurut Sumandiyo Hadi diantaranya meliputi keutuhan, variasi, repetisi, transisi, rangkaian, dan klimasks ( Y Sumandiyo Hadi, 2012; 41). Masing-masing dipahami sebgai berikut.

\section{a. Keutuhan}

Di dalam Tari Ganjur pada Upacara Erau Adat Kutai Kartanegara Ing Martadipura keutuhan tercipta dengan adanya keterkaitan antara aspek- aspek kebentukan diantara sebagai berikut : Pada bagian awal tari Ganjur pada Upacara Erau Adat Kutai Kartanegara Ing Martadipura terdiri dari motif langkah yang dilakukan secara serempak, kemudian dilanjutkan dengan motif ancang. Pada bagian tengah terdiri dari motif adu Gada, dengan gerak seperti perang Gada, tetapi pada bagian akhirnya tidak ada yang menang dan kalah. Bagian akhir pada tarian ini adalah motif 
pupus yang bertanda bahwa tarian ini telah berakhir. Dalam tarian ini gerak penyambung dari motif ke motif lainnya adalah gerak langkah, setiap motif dilakukan dengan serempak agar menampilkan kesan yang utuh, dengan pola lantai garis lurus sejajar, kurus kedepan, dan lurus ke belakang.

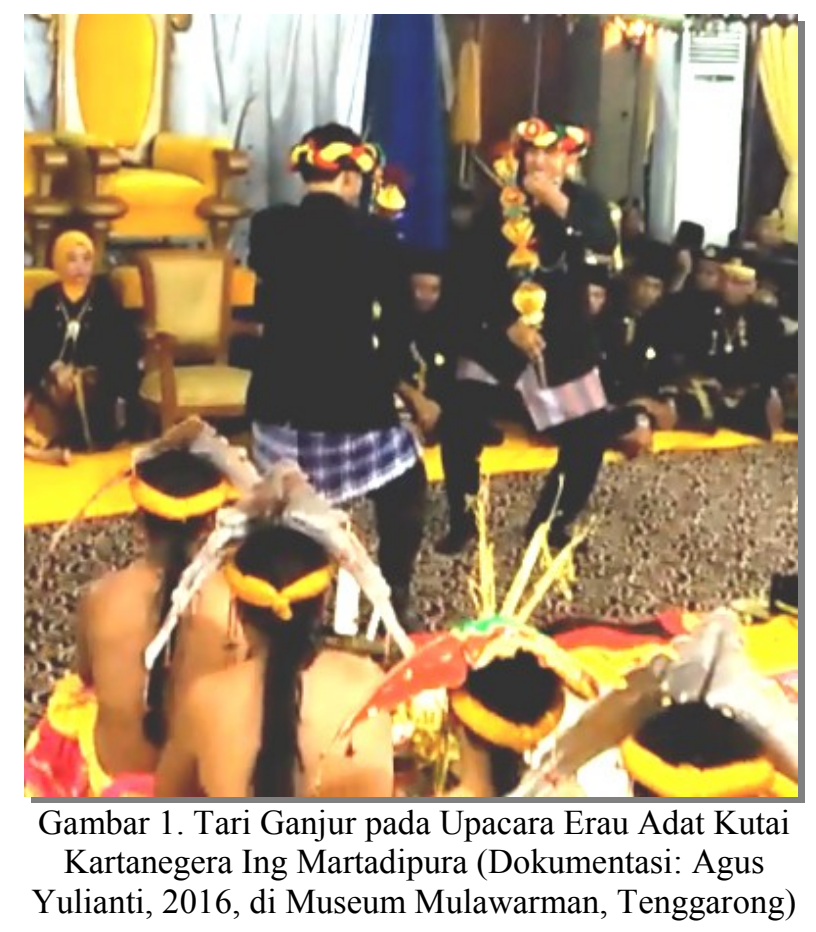

\section{b. Variasi}

Di dalam Tari Ganjur pada Upacara Erau Adat Kutai Kartanegara Ing Martadipura variasi dapat dilihat dari arah hadap, level, dan pergantian posisi penari. Variasi arah hadap yang sering dilakukan yaitu saling berhadapan, kemudian saling membelakangi satu sama lain. Pada variasi level terdapat level rendah dan level sedang yang sering dilakukan oleh penari, kemudian perpindahan penari terdapat variasi yaitu perpindahan penari dari sisi kanan dan kiri, lalu perpindahan dari depan dan belakang. Untuk mengenai variasi gerak di dalam tari ganjur ini tidak terdapat variasi gerak, karena gerakan tari Ganjur banyak terdapat pengulangan gerak.

\section{c. Repetisi (Pengulangan)}

Di dalam Tari Ganjur pada Upacara Erau Adat Kutai Kartanegara Ing Martadipura setiap motif gerak yang dilakukan oleh penari selalu terdapat pengulangan gerakan dua atau tiga kali dalam satu frase gerak. Pengulangan ini dilakukan agar penonton dapat memahami pesan yang disampaikan dalam Tari Ganjur pada Upacara Erau Adat Kutai Kartanegara Ing Martadipura.

\section{d. Transisi ( Perpindahan )}

Tari Ganjur pada Upacara Erau Adat Kutai Kartanegara Ing Martadipura tidak terdapat motif transisi atau sendi pada tari Jawa, hanya mempunyai motif pokok atau utama. Gerakan pokok atau utama telah digunakan sebagai motif transisi atau untuk perpindahan pola lantaiyaitu motif Langkah, Motif langkah merupakan sebuah gerak yang di ulang-ulang, kemudian menjadi transisi gerak, setiap ada perpindahan gerak dilakuakn dahulu dengan gerak langkah lalu dilanjutkan dengan gerak selanjutnya.

\section{e. Rangkaian}

Tari Ganjur pada Upacara Erau Adat Kutai Kartanegara Ing Martadipura dirangkain sedemikian rupa supaya menjadi sebuah pertunjukan yang menyampaikan pesan yang 


\section{JOGED}

ISSN: $1858-3989$
Agus Yulianti (ANALISIS KOREOGRAFI TARI GANJUR PADA UPACARA ADAT ERAU KUTAI KERTANEGARA KABUPATEN KUTAI KERTANEGARA, KALIMANTAN TIMUR) jelas pada Upacara Erau Adat Kutai Kartanegara Ing Martadipura. Tarian ini dirangakai dari motif langkah yang dimana geraknya seperti menjaga keamanan daerah sekeliling Tiang Ayu, kemudian dilanjutkan dengan motif ancang yang dilakukan dengan seperti bersiap-siap akan terjadinya perang, lalu dilanjutkan denga motif adu Gada pada motif ini terjadi perang satu sama lain antara penari, dan di akhiri denga motif pupus yang berarti bahwa tarian ini telah berakhir dan di dalam perang Gada tadi tidak ada yang memang dan kalah.

\section{f. Klimaks}

Di dalam Tari Ganjur pada Upacara Erau adat Kutai Kartanegara Ing Martadipura terdapat klimaks pada motif adu Gada. Pada motif ini terlihat klimaks dari tarian ini, yang dimana gerak saling berperang Gada antar penari membuat tarian ini terlihat menuju klimaks dengan diakhiri pada perang tidak ada yang menang dan tidak ada yang kalah. Klimaks pada tarian ini juga terlihat pada iringan musiknya yang temponya berubah dari lambat menjadi cepat seperti memuncak.

\section{Aspek Teknik}

Teknik dapat dipahami sebagai cara mengerjakan seluruh proses baik fisik maupun mental yang memungkinkan para penari mewujudkan pengalaman estetisnya dalam sebuah komposisi tari, sebagaimana keterampilan untuk melakukannya. Tari Ganjur pada Upacara Erau Adat Kutai Kartanegara Ing Martadipura teknik instrumennya terbagi menjadi beberapa bagian yaitu :

a. Kepala

Sikap dasar kepala yang terdapat dalam Tari Ganjur pada Upacara Erau Adat Kutai Kartanegara Ing Martadipura adalah tolehan. Dalam tarian ini sikap tolehan menjadi sikap kepala yang pokok pada tarian tersebut, yang dilakukan dengan cara arah hadap muka yang awalnya ke depan kemudian leher digerakkan ke arah samping kiri, dan tolehan pada tari ini menyesuaikan gerak badan penari. Misalnya saja gerak badan ke kiri maka tolehannya pun ke kiri.

\section{b. Tangan}

Telah dijelaskan pada bagian awal bahwa Tari Ganjur pada Upacara Erau Adat Kutai Kartanegara Ing Martadipura terdapat kesamaan gerak pada tari klasik gaya Surakarta dan Yogyakarta. Di dalam Tari Ganjur Upacara Erau adat Kutai Kartanegara Ing Martadipura terdapat tiga sikap tangan di antaranya ngithing, ukel, dan seblak. Pada gerak tangan dalam Tari Ganjur pada Upacara Erau Adat Kutai Kartanegara cara melakukannya sikap tangan ini sama dengan sikap tangan yang ada pada tari klasik gaya Surakarta dan Yogyakarta. 
c. Badan

Sikap badan merupakan faktor yang penting dalam sebuah tari, karena jika tidak dapat memenuhi patokan atau sikap badan akan dapat mempengaruhi pada gerak yang dilakukan, misalnya pada tari klasik gaya Yogyakarta memiliki aturan dimana posisi tulang belikat datar, dada tegak, membusungkan dada, perut kempis. Sama halnya dalam Tari Ganjur Upacara Erau Adat Kutai Kartanegara Ing Martadipura sikap badan juga harus diperhatikan dan dilakukan dengan benar. Posisi badan dalam tarian ini yaitu dada tegak lurus, badan tegak menghadap ke depan, dan membusungkan dada.

\section{d. Kaki}

Sikap atau gerak kaki mempunyai fungsi yang sangat penting sekali, karena kaki menjadi penopang atau penumpu badan, yang sebagai kekuatan dan keseimbangan dalam gerak. Sikap kaki dalam Tari Ganjur Upacara Erau adat Kutai Kartanegara Ing Martadipura mendapat kesamaan pada gerak kaki tari klasik gaya Surakarta dan Yogyakarta yaitu mendhak dan tayungan. Mendhak adalah posisi berdiri merendah, dengan sikap badan berdiri tegak lurus, lalu pangkal paha kanan dan kiri ditekan menurun hingga lutut kanan dan kiri menekuk ke samping. Pada motif Langkah hampir menyerupai dengan gerak tayungan pada tari klasik gaya Yogyakarta. Dalam Tari Ganjur gerak kaki pada motif Langkah adalah kaki kanan diangkat di depan kaki kiri, kemudian diletakan di depan kaki kiri, dan posisi kaki menjadi menyilang dan gerakan kaki ini dilakukan secara bergantian.

Peneliti mengamati teknik gerak yang dilakukan oleh para penari Tari Ganjur sangatlah kurang. Ketika mereka menarikan tarian seperti tidak serius dan tampak kendor. Dari beberapa malam peneliti mengamati tari tersebut, mereka melakukan gerak tarinya hanya sebatas yang mereka bisa, tanpa memikirkan teknik geraknya. Bisa jadi karena para penari bukan berasal dari sekolah seni, sehingga pengetahuan akan teknik dan kebentukan tubuh sangatlah kurang. Tetapi mungkin inilah menjadi ciri khas tersendiri untuk Tari Ganjur. Walaupun mereka melakukan tidak dengan serius tetapi tarian itu memiliki arti dan makna tersendiri dalam upacara Erau adat Kutai Kartanegara Ing Martadipura. Alangkah baiknya dilakukan dengan secara serius agar terlihat keindahannya dalam setiap gerakan yang dilakukan oleh penari, dan akan menambah nilai estetik tersendiri dalam tarian tersebut. 


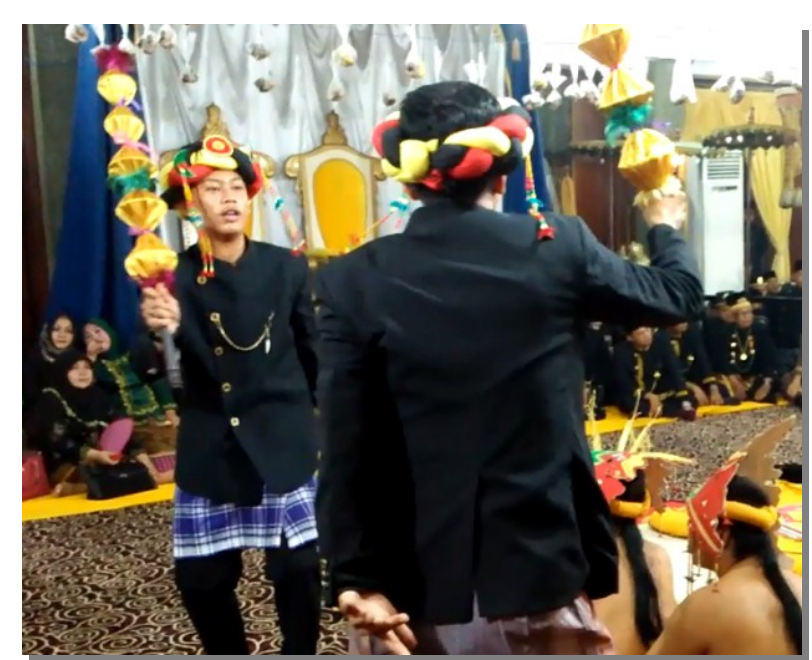

Gambar 2.Salah satu motif gerak tari Ganjur Salapada Upacara Erau Adat Kutai Kartanegara Ing Martadipura (Dokumentasi: Agus Yulianti, 2016, di Museum Mulawarman, Tenggarong)

\section{Aspek Isi}

Pendekatan koreografi sebagai konteks isi ( concent ) yang artinya melihat bentuk atau sosok tarian yang nampak empirik dari struktur luarnya ( surface structure) dan mengandung arti dari struktur di dalamnya ( depp stucture ) ( Y Sumandiyo Hadi, 2012; 55). Isi juga dapat diartikan sebagai pokok atau inti dari sebuah koreografi atau pokok permasalahan dari sebuah karya tari. Di dalam Tari Ganjur Upacara Erau Adat Kutai Kartanegara Ing Martadipura terdapat pendekatan koreografi sebagai konteks isi, diantaranya konteks isi sebagai tema gerak, konteks isi sebagai tema cerita, dan konteks isi sebagai simbolik, berikut akan di paparkan :

a. Konteks isi sebagai tema gerak

Tari Ganjur pada upacara Erau adat Kutai Kartanegara Ing Martadipura terdapat tema gerak yang berupa tipe studi. Tipe studi yaitu memandang kepentingan elemen gerak itu sendiri sebagai materi utama tari dan lebih mengkonsentrasikan studi teknik gerak. Misalnya pada motif langkah, gerakan ini bukanlah seperti gerakan melangkah pada umumnya, melainkan gerakan ini di dasari oleh rasa dalam sebuah tarian, sehingga menimbulkan keindahan pada gerakan ini. Jika dilihat gerakan ini seperti biasa saja, tetapi sebenarnya gerakan ini menyampaikan pesan untuk menjaga sekeliling Tiang Ayu dari rohroh jahat. Dilihat dari gerkannya yang mengelilingi Tiang Ayu, bertujuan agar acara Bepelas Sultan berjalan dengan lancar dan tidak ada hambatan.

b. Konteks isi sebagai tema cerita

Bedasarkan tema yang digarap, dalam bentuk pertunjukan Tari Ganjur pada upacara Erau adat Kutai Kartanegara termasuk dalam tema literer. Tari Ganjur pada upacara Erau adat Kutai Kartanegara Ing Martadipura termasuk dalam tema literer karena terlihat dari gerakan Tari Ganjur tampak menyampaikan pesan untuk menjaga keamanan Tiang Ayu dari gangguan makhluk gaib atau roh-roh jahat yang ingin mengganggu kelancaran acara Bepelas Sultan. Menurut narasumber menceritakan bahwa Tari Ganjur menurunkan Pangeran Sri Ganjur dan Sang hyang Gamboh, untuk menjaga keamanan Tiang Ayu dilihat dari area 
menarinya ke arah empat penjuru arah mata angin dan mengelilingi Tiang Ayu.

Berdasarkan uraian tersebut, tema dari Tari Ganjur pada upacara Erau Adat Kutai Kartanegara Ing Martadipura adalah keamanan. Keamanan dapat diartikan hal utama yang berkaitan dengan nasib sekumpulan manusia, dan berkaitan dengan keyakinan kebebasan dari suatu ancaman. Di dalam upacara Erau adat Kutai Kartanegara Ing Martadipura pada acara Bepelas Sultan, keamanan dapat diartikan sebagai menjaga sebuah keamanan Tiang Ayu dari gangguan makhluk halus dan roh-roh jahat yang ingin mengganggu acara Bepelas Sultan tersebut. Tari Ganjur termasuk dalam tema keamanan karena berkaitan langsung dengan gerak-gerak tari Ganjur pada upacara Erau Adat Kutai Kartanegara Ing Martadipura. Dilihat dari bentuk penyajian, pada segi gerak Tari Ganjur yaitu mengelilingi Tiang Ayu, dapat diartikan ketika penari menarikan Tari Ganjur dengan mengelilingi Tiang Ayu, dan menjaga keamanan di sekeliling Tiang Ayu .

c. Konteks isi sebagai tema simbolik Di dalam Tari Ganjur pada Upacara Erau adat Kutai Kartanegara Ing Martadipura konteks isi sebagai tema simbolik dapat diartikan sebagai bentuk dan cara ungkap. Tari Ganjur diungkap dengan pola koreografi kelompok yang mengandung unsur dramatik. Pada penyajian tari Ganjur dalam upacara
Erau adat Kutai Kartanegara Ing Martadipura terdapat penggambaran peristiwa yang ditunjukkan antara penari saling menjaga keamanan Tiang Ayu dan terdapat gerak semacam perang seperti mengadu Gada. Pada bagian akhir dari pertunjukan yang merupakan penutup yaitu memberi gambaran dalam perang atau mengadu Gada itu tidak ada yang menang dan tidak ada juga yang kalah. Cara ungkap dalam tari dibedakan menjadi dua, yaitu simbolis dan representasional. Gerak representasional dalam tari Ganjur pada Upacara Erau adat Kutai Kartanegara sebagai contoh pada gerak melangkah, dalam hal ini gerak melangkah yang dimaksud bukanlah pengertian dalam kehidupan sehari-hari melainkan gerak melangkah yang didasari dengan bentuk estetis dan rasa dalam sebuah tarian. Gerak melangkah ini memang seperti gerak berjalan, analisisnya jika berjalan seperti biasanya dilakukan dengan tangan yang bergerak secara spontan atau dengan sendirinya, tetapi dalam tarian ini gerak berjalan yang diberi bentuk keindahan, sedangkan gerak tangan telah diatur agar gerak antara tangan dan kaki terlihat seimbang, maka dari itu dapat dikatakan dengan gerak simbolik representasional. 
JOGED

ISSN: $1858-3989$
Agus Yulianti (ANALISIS KOREOGRAFI TARI GANJUR PADA UPACARA ADAT ERAU KUTAI KERTANEGARA KABUPATEN KUTAI KERTANEGARA, KALIMANTAN TIMUR)
B. Aspek Gerak Tari Ganjur Pada Upacara Erau adat Kutai Kartanegara Ing Martadipura.

Membicarakan tentang elemen dasar koreografi sesungguhnya tidak dapat terpisahkan antara kesatuan elemen ruang, waktu dan tenaga. Hubungan antara ketiganya merupakan hal pokok dari sifat koreografi. Tari Ganjur pada upacara Erau adat Kutai Kartangara Ing Martadipura dapat ditinjau dalam aspek ruang, waktu, dan tenaga. Berikut akan dipaparkan mengenai bentuk penyajian tari Ganjur pada upacara Erau adat Kutai Kartanegara Ing Martadipura dalam aspek ruang, waktu dan tenaga :

\section{Aspek Ruang}

Ruang merupakan sesuatu yang tidak bergerak dan diam sehingga gerak yang terjadi di dalamnya mengintodusir waktu dengan demikian, cara tersebut dapat mewujudkan ruang sebagai suatu bentuk atau suatu ekspresi khusus yang berhubungan dengan waktu yang dinamis dalam suatu gerak ( Y Sumandiyo Hadi, 2007; 54). Aspek ruang yang terdapat dalam Tari Ganjur Pada Upacara Erau adat Kutai Kartanegara Ing Martadipura digambarkan dengan level, pola lantai, dan arah. Berikut akan dipaparkan mengenai aspek ruang yang ada pada Tari Ganjur :

a. Level
Tari Ganjur pada Upacara Erau Adat Kutai Kartanegara Ing Martadipura terdapat permainan level dalam setiap motif yang dilakukan oleh penari. Permainan level pada motif gerak Tari Ganjur yaitu level sedang dan level rendah, misalnya pada motif Langkah pada hitungan 1-4 posisi penari melakukan level sedang, kemudian pada hitungan 5-8 penari melakukan posisi level rendah.

b. Pola Lantai

Pada Tari Ganjur upacara Erau adat Kutai Kartanegara menggunakan pola lantai garis lurus dengan desain lurus sejajar, lurus ke depan, ke belakang. Peneliti melihat desain pola lantai dari arah belakang sesudah pintu masuk Museum Mulawarman, sehingga pola lantai dalam tari Ganjur ini membentuk pola lantai berpasangan, sejajar, ke belakang dan saling membelakangi penari satu sama lain.

c. Arah

Tari Ganjur pada Upacara Erau adat Kutai Kartanegara Ing Martadipura memiliki arah lintasan gerak yaitu garis lurus dengan desain lurus sejajar, lurus ke depan penari, dan lurus ke arah belakang penari, yang terlihat dari segi gerak yang dilakukan oleh penari yaitu mengelilingi Tiang Ayu. 


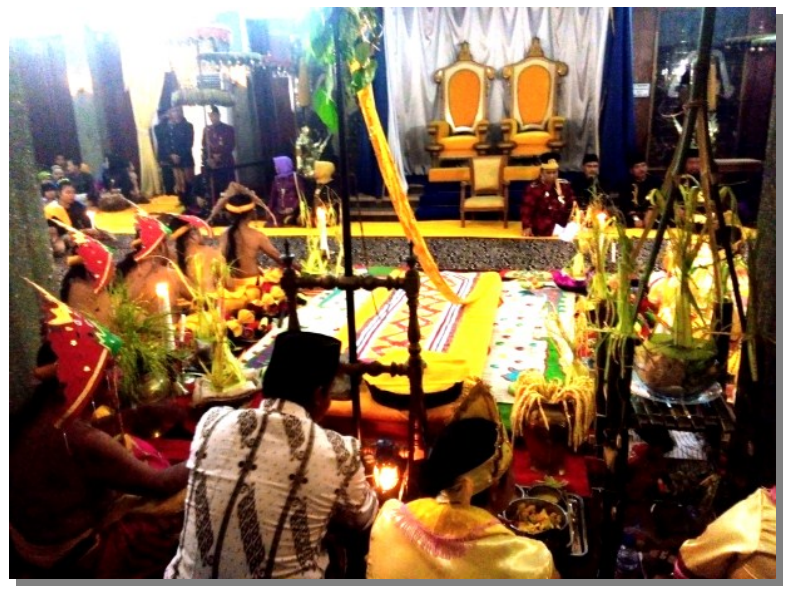

Gambar 3. Area pementasan Tari Ganjur, dalam acara Bepelas Sultan pada Upacara Erau adat Kutai Kartanegara Ing Martadipura. (Dokumentasi, Agus Yulianti, 2016, di Museum Mulawarman, Tenggarong.)

\section{III.Aspek Waktu}

Waktu dalam tari dapat dipahami sebagai elemen estetis, karena aspek waktu sebagai suatu alat untuk memperkuat hubungan-hubungan kekuatan dari rangkaian gerak. alam Tari Ganjur pada Upacara Erau Adat Kutai Kartanegara Ing Martadipura dapat ditinjau dari struktur waktu aspek tempo, ritme dan durasi.

\section{a. Tempo}

Tari Ganjur Upacara Erau adat Kutai Kartanegara Ing Martadipura tempo yang dilakukan oleh penari dari awal menari dengan tempo yang sama, karena penari melakukan gerak dengan tempo yang lambat, sehingga penonton dapat merasakan, dan menikmati kekuatan gerak yang dilakukan oleh penari. Perpindahan gerak lambat ke gerak yang cepat sangat terasa pada tarian ini, perpindahan gerakan ini pun diberi aba-aba oleh iringan musik yaitu Gendang, ketika ketukan kendang menjadi cepat maka itu telah terjadi perpindahan gerak lambat ke gerak cepat yang terlihat pada motif ancang menuju ke motif adu Gada, karena motif adu gada ialah motif yang dikatakan sebagai perang Gada sehingga tempo untuk gerakan ini terbilang lebih cepat dari pada motif sebelumnya. Saat perpindahan dari gerak lambat ke gerak cepat penari melakukannya dengan sangat hati-hati, dan tidak tergesa-gesa, sehingga menimbulkan keindahan dalam tarian tersebut, dan membuat penontop tetap menikmati tarian ini.

\section{b. Ritme}

Tari Ganjur pada Upacara Erau Adat Kutai Kartanegara Ing Martadipura melakukan pengulangan gerakan atau motif gerak dengan jarak waktu yang berjarak sama sehingga menimbulkan aliran atau irama yang ajeg atau sama. Adapun perpindahan antara gerak lambat ke gerak cepat, yang terlihat pada motif angcang menuju ke motif adu Gada, ritme dalam tarian ini pun tetap ajeg atau sama tidak ada perubahannya.

\section{c. Durasi}

Tari Ganjur pada Upacara Erau Adat Kutai Kartanegara Ing Martadipura ini berdurasi \pm 10 menit, tetapi sebelum melakukan tarian ini ada beberapa kegiatan yang dilakukan terlebih dahulu. Waktu untuk pementasan Tari Ganjur pada upacara Erau adat Kutai Kartanegara ini dilakukan secara 


\section{JOGED}

ISSN: $1858-3989$
Agus Yulianti (ANALISIS KOREOGRAFI TARI GANJUR PADA UPACARA ADAT ERAU KUTAI KERTANEGARA KABUPATEN KUTAI KERTANEGARA, KALIMANTAN TIMUR) tertutup karena bersifat ritual. Upacara Erau adat Kutai Kartanegara Ing Martadipura diselenggarakan selama tujuh hari delapan malam, maka setiap malam harinya dilakukan acara Bepelas Sultan, dan tari Ganjur turut hadir dalam rangkaian acara Bepelas Sultan.

\section{Aspek Tenaga}

Tenaga dapat dipahami sebagai usaha mengawali, mengendalikan, dan menghentikan gerak. Tari Ganjur pada Upacara Erau adat Kutai Kartanegara Ing Martadipura dalam bentuk penyajiannya terbagi menjadi tiga bagian, terlihat pada perpindahan gerak atau motif yang terpaku pada iringan musiknya. Pada saat perpindahan motif ancang ke motif adu Gada terlihat jelas pengaruh dari iringan musiknya yang memberikan aba-aba bahwa akan ke motif adu Gada, karena penari dan pemusiknya pun sama-sama memberi aba-aba bahwa akan terjadi perpindahan motif. Tenaga yang dibutuhkan dalam melakukan tarian ini sangat besar, karena dari awal tarian ini dimulai penari melakukan gerakan yang pelan atau lambat, kemudian adanya perpindahan gerak yang cepat sekitar dua kali pengulangan motif gerak, setelan itu kembali lagi ke gerak lambat atau pelan, sehingga dapat dikatakan menggunakan tenaga yang besar. Salah satu motif yang menggunakan tenaga besar ialah motif adu Gada, motif ini dilakukan dengan gerakan pelan kemudian ke gerakan yang cepat, mengikuti aba-aba dari iringan musik, karena pada motif ini menggambarkan perang antara penari yaitu perang gada.

Tenaga juga dipahami sebagai unsur pokok dalam sebuah tarian tersebut, jika didalam tari Klasik gaya Yogyakarta penggunaan tenaga berkaitan dengan sawiji, greged, sengguh, ora mingkuh. Agar tarian menjadi greged tidak sekedar fisikal saja, maka harus menggunakan tenaga yang jelas dan kuat. Sehingga ketika dalam menari tidak menggunakan tenaga akan terlihat sangat tidak bagus, dan penontonpun tidak dapat menikmati pertunjukan tarian tersebut.

\section{PENUTUP}

Tari Ganjur merupakan sebuah kesenian yang berkembang serta dipelihara dan dilestarikan oleh masyarakat Kesultanan Kutai Kartanegara Ing Martadipura. Tari Ganjur merupakan suatu pertunjukan yang berbentuk upacara, bersifat ritual, dan hanya dipentaskan pada upacara-upacara tertentu dan secara tertutup, misalnya saja pada upacara penobatan Raja, bahkan selalu hadir dalam upacara Erau adat Kutai Kartanegara Ing Martadipura. Tarian ini merupakan tarian pecampuran antar dua budaya yaitu, budaya Kutai dan Jawa, yang terlihat pada segi gerak dan instrument yang digunakan dalam mengiringi tari Ganjur. Berdasarkan bentuk pertunjukan tari Ganjur pada upacara Erau adat Kutai Kartanegara Ing Martadipura 
terdapat satu bagian, karena dari segi geraknya tidak ada variasi, dan terdapat banyak pengulangan dari setiap motifnya, serta iringan musiknya pun monoton. Pertunjukan tari Ganjur didukung dari beberapa aspek, diantaranya aspek gerak dan properti yang digunakan oleh penari. Properti pada tari Ganjur adalah Gada yang terbuat dari kayu berlapiskan kain yang biasanya disebut dengan ganjur.

Tari Ganjur dan beberapa aspek pendukungnya merupakan satu kesatuan yang tidak dapat dipisahkan dalam suatu bentuk pertunjukan. Kehadiran tari Ganjur dalam upacara Erau adat Kutai Kartanegara Ing Martadipura mempunyai peranan yang sangat penting dalam acara Bepelas sultan. Tarian ini diperuntukan menurunkan sangyang Sri Gamboh dan Pangeran Sri Ganjur untuk menjaga keamanan di sekeliling Tiang Ayu. Tari Ganjur pun termasuk dalam simbol kekuasan Sultan, yang terlihat bentuk pertunjukannya tarian ini hanya di hadirkan dalam upacara-upacara tertentu dan tertutup, sedangkan penari dan pemusiknya tidak sembarangan orang, melainkan harus dari keturunan atau kerabat Kesultanan Kutai Kartanegara Ing Martadipura. Keberadaan Tari Ganjur yang merupakan rangkaian dari acara Bepelas Sultan dalam upacara Erau adat Kutai Kartanegara Ing Martadipura, tidak dapat disajikan tanpa adanya Gamelan Kutai, dan juga tarian ini berperan penting dalam upacara Erau, karena tanpa adanya atau tidak dilaksanankannya tarian ini di dalam susunan upacara Erau, maka diyakini bahwa upacara Erau dalam pelaksanaannya tidak akan berjalan lancar. Tari Ganjur juga selalu hadir setiap acara Bepelas Sultan berlangsung, walaupun ada beberapa malam tidak dilaksanakan tetapi itu sudah ada aturan dari sananya, sehingga keberadaan Tari Ganjur ini sangat berkaitan dan tidak dapat terlepas dari upacara Erau adat Kutai Kartanegara Ing Martadipura khususnya pada malam Bepelas Sultan.

\section{DAFTAR SUMBER ACUAN}

\section{A. Sumber Tertulis}

Hadi, Y. Sumandiyo 2012. KoreografiBentukTeknik-Isi : Pendekatan Koreografi, Yogyakarta : Cipta Media. . 2007. Kajian Tari Teks dan Konteks : Tari dalam Konteks Berbagai Macam Kepercayaan. Yogyakarta : Pustaka.

Jacqueline Smith, A Pratical Guide for Teacher, 1976, terjemahan Ben Suharto. 1983. Komposisi Tari: sebuah Pertunjukan Praktis bagi Guru. Yogyakarta: Ikalisti.

La Meri. 1976. Dance Composition: The Basic Elemen, terjemahan Soedarsono. 1976. Elemen-elemen Dasar Komposisi Tari, Jakarta : Akademi Seni Tari Indonesia.

Sal Murgiyanto. 1986. Dasar- Dasar Koreografi Tari, dalam pengetahuan Elementer Tari dan Beberapa Masalah 
JOGED

ISSN: $1858-3989$

Tari. Jakarta: Direktorat Kesenian Proyek Pembangunan Kesenian Jakarta

Departemen Pendidikan dan

Kebudayaan.

Soedarsono. 1986. Pengantar Pengetahuan dan Komposisi Tari, dalam Pengetahuan Elementer Tari dan Beberapa Masalah Tari. Jakarta: Direktorat Kesenian Proyek Pengembangan Kesenian Jakarta Departemen Pendidikan Dan Kebudayaan.

1977. Tari-tarian Indonesia I. Jakarta: Proyek Pengembangan Kebudayaan Direktorat Jendral Kebudayaan.

Winata, Adji Zamrul Syalehin. 2000. Erau Adat Kesultanan Kutai Kartanegara Ing Martadipura

Murhansyah. 2006. Erau Kemilau Kearifan Masa Silam. Pondok Gede: Ganeca Exact.

\section{B. Sumber Lisan}

Adji Ali Zainalfaisal,SE,MM. 56 tahun, Anak Sultan Kutai Kartanegara.

Adji Muhammad Aflianto, 58 tahun, mantan penari tari Ganjur dan kerabat Keraton Kutai Kartanegara. 